\title{
A Tradução como trabalho da memória e traço mnêmico
}

\section{Susana Kampff Lages - Universidade Federal Fluminense}

Resumo: O trabalho pretende realizar uma leitura do ensaio benjaminiano "A tarefa do tradutor", buscando identificar analogias entre o trabalho (a 'tarefa') do tradutor e o trabalho psíquico da rememoração. Sendo mutuamente determinantes, tradução e rememoração são inseparáveis: todo processo rememorativo implica tradução e toda tradução, ao se concretizar, exibe traços de sua relação rememorativa com o texto original. No contexto de uma reflexão sobre as traços mnêmicos (Erinnerungsspuren), é eloquente a imagem acústica do eco, utilizada por Benjamin, que põe em cena a tradução como produto de um complexa relação entre língua do original e língua da tradução, por um lado, e entre o original e outros textos que o antecedem, por outro.

Palavras-chave: tradução - rememoração - eco

Num livro fascinante, o filólogo e teórico da literatura alemão Harald Weinrich persegue, de um ponto de vista bastante original, as pistas que a arte da memória deixou na tradição literária e filosófica ocidental. A originalidade de sua proposta de leitura em Lete. Arte e crítica do esquecimento, está no fato de ele deslocar o foco de interesse, ao longo dos dez capítulos que compõem a obra, para a reflexão sobre o esquecimento, a necessária e ela mesma muitas vezes esquecida contraparte da memória. Nessa obra de grande erudição, Weinrich lê as figurações da memória e do esquecimento desde a Antiguidade clássica, de Simônides de Ceos, Homero e Ovídio até chegar, num passeio memorável pela literatura e filosofia dos séculos subseqüentes, a escritores do século XX com suas memoráveis catástrofes. Entretanto, nessa obra de vulto não há um capítulo sobre o papel do esquecimento na obra de um certo leitor de Nietzsche, Freud e Proust: aquele escritor "estrangeiro de nacionalidade indeterminada mas de origem alemã": Walter Benjamin. Weinrich o teria esquecido? Difícil - e inócuo dizer. Mais adequado para um leitor da obra benjaminiana é aproveitar dessa lacuna do livro de Weinrich e buscar preenchê-la, ainda que de modo igualmente lacunar. Detlev Schöttker (2000: 260), em seu competente ensaio "Erinnern" [Recordar], que consta do primeiro volume da antologia Benjamins Begriffe [Conceitos benjaminianos], indica o final dos anos 20 do século passado como marco inicial do interesse de Walter Benjamin pelo fenômeno da recordação [Erinnerung], e com ele toda uma série de transformações no curso de seu pensamento. Desse ponto de vista, o divisor de águas em sua obra teria sido o seu intenso contato com a obra de Proust, nomeadamente com a Recherche, da qual Benjamin traduziu três volumes, em parceria com Franz Hessel, e sobre a qual escreveu, posteriormente, o ensaio "A imagem de Proust".

No entanto, quero avançar aqui a hipótese de que o interesse pelo tema da memória e do esquecimento se manifesta já um pouco antes da escrita desse comentário sobre a obra de Proust, uma obra que praticamente não deixa espaço para que o leitor/comentador deixe de refletir sobre os movimentos do lembrar e do esquecer. A 
preocupação com essa dinâmica da memória surge no contexto de uma reflexão sobre um particular modo de escrita, que ocupou a atenção e a própria escrita de Benjamin intensamente justo naqueles anos: a tradução. Nos dois escritos de Walter Benjamin "Sobre a linguagem em geral e sobre a língua dos homens" e "A tarefa do tradutor" aparecem indícios de uma singular ligação entre traduzir/ler/escrever e lembrar/esquecer.

Ao tentar definir, no ensaio "A tarefa do tradutor", a relação entre original e tradução em termos de sua traduzibilidade e concomitante intraduzibilidade (e já foi suficientemente demonstrado que inexistem elementos de fato intraduzíveis, elementos que parecem intraduzíveis são apenas indícios daquele resto, rastro de sentido para que a língua/as línguas apontam), Benjamin recorre a um raciocínio bastante intrincado que tem como centro justamente a relação entre esquecer e rememorar, e a situa em dois planos diferentes: no seio da vida humana e na relação do ser humano com um Deus. $\mathrm{Na}$ vida e no tempo, atua o esquecer; em Deus, o rememorar:

Assim, poder-se-ia falar de uma vida ou de um instante inesquecível, mesmo que todos os homens o tivessem esquecido. Pois se sua essência exigisse não serem esquecidos, aquele predicado não conteria nada de falso, apenas uma exigência à qual os homens não correspondem e, ao mesmo tempo, também a referência a uma esfera, na qual essa exigência fosse correspondida: a uma rememoração de Deus [ein Gedenken Gottes]. De maneira análoga, a traduzibilidade de composições de linguagem [Sprachgebilde ${ }^{1}$ deveria ser levada em consideração, ainda que elas fossem intraduzíveis para os homens. E, não seriam elas, até certo ponto, de fato intraduzíveis, se partirmos de um rigoroso conceito de tradução? (grifo nosso) ${ }^{2}$

Benjamin tenta dar conta da questão da traduzibilidade (e por trás de seu argumento ressoam séculos de "objeções prejudiciais" a tentar desmentir a evidência da traduzibilidade e da tradução em geral), por meio de um raciocínio que põe em relevo, pelo negativo, o memorável, evocando-o como o inesquecível, por um lado; por outro, ele estabelece, tomando a relação lembrar/esquecer como termo comparativo, uma relação íntima entre o traduzível e o intraduzível, como sendo elementos integrantes de um mesmo movimento, que, no entanto, não pode mudar de direção. Ou seja, por meio da traduzibilidade, que contém em germe sua(s) tradução ou suas traduções potenciais, os originais por assim dizer determinam suas traduções; já o contrário não ocorre:

É mais do que evidente que uma tradução, por melhor que seja, jamais poderá significar algo para o original. Entretanto, graças à traduzibilidade do original, a tradução se encontra com ele em íntima conexão. E, aliás, essa conexão é tanto mais íntima quanto para o próprio original ela nada mais significa. É lícito chamá-la de natural ou, mais precisamente, de conexão de vida. ${ }^{3}$

De um ponto de vista do senso comum, essa relação de vida entre original e tradução é de natureza indicial, "natural", diz Benjamin. Em outro momento do ensaio, Benjamin expressa esse caráter indicial da relação entre os dois textos em termos das diferentes motivações, intenções que movem a escrita de seus autores, respectivamente o escritor e o tradutor: “(...)a intenção do escritor é ingênua, primeira, intuitiva; a do tradutor, derivada, última, ideativa.”, buscando com essa distinção caracterizar a singularidade do trabalho escritural, da "tarefa", do tradutor e ele o faz sem qualquer prejulgamento em favor da "tarefa do escritor" em detrimento da "tarefa do tradutor". A 
inclusão da palavra "ideenhaft" para caracterizar a intenção da escrita tradutória conferelhe aqui um estatuto quase que superior ao da escrita literária em geral, em sua primeiridade ingênua, intuitiva. Não se encontram aqui, nessa distinção, palavras que pudessem caracterizar a relação entre original e tradução em termos de uma cópia ou reprodução, de uma repetição de um "mesmo" texto em outra língua. Ou seja, os rastros do original que possivelmente poderão ser identificados na obra traduzida não consistem em elementos que indicam qualquer tipo de semelhança entre uma e outra. De fato, no ensaio sobre "A tarefa do tradutor", Benjamin defende a idéia de que a relação entre original e tradução não teria caráter mimético-imitativo, e sim, uma relação de afinidade (Verwandtschaft), que não se basearia em qualquer semelhança sensível (esse argumento será desenvolvido na sua assim-chamada "segunda" teoria da linguagem, que gravita em torno dos textos "A doutrina das semelhanças" e "Sobre a capacidade mimética"):

Se a afinidade entre as línguas se anuncia na tradução, isso ocorre de modo distinto da vaga semelhança entre reprodução [Nachbildung] e original. Como também é evidente, em geral, que afinidade não implica necessariamente semelhança. É também nessa medida que o conceito de afinidade está em consonância, nesse contexto, com seu emprego mais restrito, sendo que em ambos os casos, ele não pode ser definido de maneira satisfatória por meio de uma identidade de proveniência, não obstante o conceito de proveniência permaneça indispensável para a definição daquele emprego mais restrito. ${ }^{4}$

Benjamin descarta considerar a tradução como uma "cópia", reprodução do original, buscando descrever a relação entre original e tradução enquanto pautada numa relação de afinidade supra-histórica entre as línguas, que apareceria só e unicamente no texto traduzido e que em última instância apontaria para um elemento comum a todas as línguas. Esse elemento resultaria do direcionamento de todas as línguas a algo que lhes seria comum e que não poderia ser apreendido por cada uma delas isoladamente, mas que surgiria como resultado de suas "intenções reciprocamente complementares" [ihrer einander ergänzenden Intentionen]. Benjamin denomina esse "algo": die reine Sprache a pura língua ou a pura linguagem. Aqui o tema da pura língua e sua relação com a tradução aparece como um vestígio do ensaio anterior sobre a linguagem, o famoso Sprachaufsatz, considerado pelo próprio Benjamin como "arcano" de seu pensamento e divulgado por ele prioritariamente apenas entre amigos mais próximos, contém em germe reflexões desenvolvidas no posterior escrito sobre a tradução:

É a tradução da linguagem das coisas para a linguagem do homem. É necessário fundar o conceito de tradução no nível mais profundo da teoria lingüística, pois ele possui alcance e poder demasiado amplos para ser tratadode uma maneira qualquer num momento posterior, como algumas vezes se pensa. Tal conceito adquire sua plena significação no entendimento de que toda língua superior (com exceção da palavra de Deus) pode ser considerada como tradução de todas as outras. Graças à relação acima mencionada entre as línguas, como uma relação entre meios de diferente densidade, que se dá a traduzibilidade das línguas entre si. A tradução é a passagem de uma língua para a outra por uma série contínua de metamorfoses. Séries contínuas de metamorfoses, e não regiões abstratas de igualdade e de similitude, é isso que a tradução percorre. ${ }^{5}$ 
Nesse texto fundador, o castigo babélico da multiplicação das línguas e a conseqüente queda na discórdia e perda de um estado harmonioso originário representa uma espécie de efeito tardio da ousadia de Adão, ao experimentar o fruto da árvore do conhecimento do bem e do mal - como se o episódio da construção da torre repetisse (traduzisse?) o daquela queda anterior. O conseqüente desaparecimento de um modo imediato de comunicação, centrado na mítica ação nomeadora de Deus e do primeiro homem, impõe aos homens traduzir, ou seja, movimentarem-se de uma língua a outra e, com isso também, a movimentarem-se de um ponto a outro da cadeia temporal, tornando presente uma obra que, do ponto de vista de sua língua original, é passada. Segundo o ensaio benjaminiano sobre a linguagem, na própria origem da linguagem humana estaria uma operação de tradução, anterior mesmo às próprias línguas: tradução do âmbito mudo da natureza para o domínio "falante" da linguagem.

Essa dimensão de fala deixa suas marcas no ensaio sobre a tradução na forma de uma imagem que se constrói em torno de um chamado, uma emissão de voz: Benjamin tenta esclarecer a singularidade da tarefa do tradutor como equivalente à singularidade da complexa relação entre as línguas da tradução e do original. Para isso, ele se utiliza da estranha imagem do eco [Echo], da ressonância [Widerhall] a um chamado, que a tradução dirigiria ao seu original para que, deixando "o interior da mata da linguagem" [innern Bergwald der Sprache] em que se encontra, ele "adentre aquele único lugar, no qual, a cada vez, o eco é capaz de reproduzir na própria língua a ressonância de uma obra da língua estrangeira" [ an demjenigen einzigen Orte hinein, wo jeweils das Echo in der eigenen den Widerhall eines Werkes der fremden Sprache zu geben vermag]. Aqui talvez valha a pena ouvirmos, em nossa tradução, a ressonância integral do eco chamado pelas palavras benjaminianas, enquanto definição da tarefa específica do tradutor:

Essa tarefa consiste em encontrar na língua para a qual se traduz a intenção a partir da qual o eco do original é nela despertado. Aqui está um traço que distingue tradução e obra poética, pois a intenção desta nunca se dirige à língua enquanto tal, à sua totalidade, mas única e imediatamente, a determinados contexto de teor de linguagem. Mas a tradução não se vê como a obra literária, mergulhada, por assim dizer, no interior da mata da linguagem, mas vê-se fora dela, diante dela e, sem penetrá-la, chama o original para que adentre aquele único lugar, no qual, a cada vez, o eco é capaz de reproduzir na própria língua a ressonância de uma obra da língua estrangeira. Sua intenção não só se dirige a algo diverso da obra literária, ou seja, a uma língua como um todo, partindo de uma obra de arte isolada, escrita numa língua estrangeira; mas sua própria intenção é outra: a intenção do escritor é ingênua, primeira, intuitiva; a do tradutor, derivada, última, ideativa. ${ }^{6}$

Após diferenciar o estatuto da obra literária original e obra traduzida por meio da imagem do eco, Benjamin conclui que esse chamado remete ao direcionamento último a um âmbito, a um só tempo, originário e futuro de reconciliação entre as línguas, o que confereria à tarefa do tradutor uma dimensão intrinsecamente messiânica:

Pois é o grande tema da integração das várias línguas em uma única, verdadeira, que acompanha o seu trabalho. Essa língua, porém, em que as frases, obras e juízos isolados jamais se entendem — razão pela qual permanecem dependentes de tradução - é aquela na qual, entretanto, as línguas coincidem entre si, 
completas e reconciliadas no seu modo de visar. No entanto, se, ao contrário, existir uma língua da verdade, na qual os segredos últimos, que o pensamento se esforça por perseguir, estão guardados sem tensão e mesmo tacitamente, então essa língua da verdade é: a verdadeira língua. ${ }^{7}$

Ao final desse enunciado de caráter messiânico, que traz a tradução para o âmbito interno da própria língua, para o qual também se precisa de tradução, ouvimos o eco de um outro momento do ensaio, em que Benjamin também remete ao universo sonoro, para tentar superar de alguma forma o "dilema insolúvel" contido no antagonismo secular que perpassa a teoria da tradução:

Fidelidade e liberdade - liberdade na reprodução do sentido e, a serviço dessa liberdade, fidelidade à palavra — são os velhos e tradicionais conceitos presentes em qualquer discussão sobre traduções. Eles parecem não mais servir para uma teoria que procura na tradução algo diferente da mera reprodução do sentido. É verdade que seu emprego tradicional vê esses conceitos sempre num dilema insolúvel. De fato, que aporte pode trazer a fidelidade para a reprodução do sentido? A fidelidade na tradução de cada palavra isolada quase nunca é capaz de reproduzir plenamente o sentido que ela possui no original. Pois, segundo sua significação literária para o original, o sentido não se esgota no visado; ele adquire essa significação precisamente pela maneira como o visado se liga, em cada palavra específica, ao modo de visar. Costuma-se expressar isso com a fórmula: as palavras carregam uma tonalidade afetiva. (grifo nosso) ${ }^{8}$

Sabemos que Benjamin foi um leitor atento de Freud, um autor cuja construção teórica, a psicanálise, assenta sobre os pilares não tanto da memória, quanto também - e sobretudo - do esquecimento, como assinala igualmente Harald Weinrich, ao intitular de "Esquecimento apaziguado e não apaziguado" o capítulo de seu livro dedicado ao papel do esquecimento em Freud. Dessa presença de Freud há também um vestígio no texto sobre a "Tarefa do Tradutor", ele está na referência às teorias psicofísicas de Gustav T. Fechner, um dos fundadores da psicologia experimental e professor de Freud em Leipzig. Ainda que suas concepções e prática clínicas fossem bastante diferentes, a influência de Fechner se estende sobre aspectos fundamentais da teoria freudiana (Freud o chamou de "Der grosse G.T. Fechner", o grande G.T. Fechner), como por ex., a idéia de um princípio do prazer e de uma pulsão de morte como reguladores do psiquismo humano. Se pensarmos no caráter dúplice da pulsão [Trieb], assim como definida por Freud como elemento originário do desejo humano, situado na fronteira entre o somático e o psíquico, e se considerarmos a importância do lento processo de rememoração da história pessoal do paciente no tratamento psicanalítico, podemos reconhecer a presença velada de Sigmund Freud, na passagem em que Benjamin cita Fechner, no início de seu ensaio:

Mas não por isso se trata de estender o império da vida sob o débil cetro da alma [Seele], da maneira tentada por Fechner; menos ainda, trata-se de poder definir a vida a partir de aspectos da animalidade, ainda menos propícios a servirem de medida, como a sensação [Empfindung], que apenas ocasionalmente é capaz de caracterizá-la. É somente quando se reconhece vida a tudo aquilo que possui história e que não constitui apenas um cenário para ela, que o conceito de vida encontra sua legitimação. ${ }^{9}$ 
Mesmo a idéia de uma tonalidade afetiva das palavras não deixa de estar em consonância com a idéia psicanalítica segundo a qual a linguagem dos sonhos ou dos sintomas deve ser compreendida tanto em sua carga afetiva, quanto nas representações que a ela se associam e que muitas vezes dela precisam ser desligadas para que o passado insidioso possa ser definitivamente esquecido e deixe de exercer sua má influência sobre o presente. A tonalidade afetiva da língua, essa espécie de contraparte positiva daqueles afetos psíquicos desprazerosos dos quais os neuróticos lutam para se livrar, inclui uma representação acústica [Gefühlston], e remete-nos, segundo Rainer Nägele, em seu ensaio "Echolalie", ${ }^{10}$ a uma abertura da língua em direção à própria língua [Öffnung der Sprache auf die Sprache], ou seja, a algo que não se deixa fixar mas que se estende nas "séries contínuas de metamorfoses (... ) que a tradução percorre". [Kontinua der Verwandlung (...) durchmisst die Übersetzung. ${ }^{11}$ ]

\begin{abstract}
This paper aims to do a reading at Walter Benjamin's essay on "The Task of the Translator" in search of analogies between the translator's work (his "task") and the mental process of recollection. Being mutually determinant, translation and recollection are inseparable: every recollecting process implies an act of translation and every translation, in its concrete manifestation, displays traces of its bond with the original text. In the context of a reflection on mnemic traces (Erinnerungsspuren), Benjamin's final acoustic image of an echo is quite eloquent, since it performs translation as the product of a complex relationship, on the one hand between the language of the original text and that of the translated text and, on the other, between the original text and other texts that preceded it in time.
\end{abstract}

Key-words: translation - recollection - echo

\title{
Referências Bibliográficas
}

BENJAMIN, Walter. A tarefa do tradutor in GAGNEBIN, Jeanne Marie. (org.) Escritos sobre mito e linguagem. Trad. Susana Kampff Lages. São Paulo: Ed. 34, 2011. p. 101-19. [ed. al. Die Aufgabe des Übersetzers in BENJAMIN, W. Kleine Prosa, Baudelaire-

Übertragungen. Ed. Tillmann Rexroth, 1972. V. 4, t. 1.p. 9-21]

. Sobre a linguagem em geral e sobre linguagem do homem in GAGNEBIN, Jeanne Marie. (org.) Escritos sobre mito e linguagem. Trad. Susana Kampff Lages. São Paulo: Ed. 34, 2011. p. 49-73. [ed. al. Über Sprache überhaupt und über die Sprache des Menschen in BENJAMIN, W. Aufsätze, Essays, Vorträge. Eds. R. Tiedemann \& H. Schweppenhäuser. 1977. Vol II, t. 1, p. 140-57.]

NÄGELE, Rainer. Echolalie in NIBBRIG,C. H. Übersetzen: Walter Benjamin. Frankfurt am Main: Suhrkamp, 2001. p. 17-37.

SCHÖTTKER, Detlev. Erinnern in OPITZ, Michael \& Wizisla, Erdmut. (orgs). Benjamins Begriffe. Frankfurt am Main: Suhrkamp, 2000. Vol. 1, p. 260-298.

WEINRICH, Heinrich. Lete. Arte e crítica do esquecimento. Rio de Janeiro: Civilização Brasileira, 2001. [ed. al. WEINRICH, H. Lethe. Kunst und Kritik des Vergessens. Munique: C.H. Beck, 1997] 


\section{Notas}

${ }^{11}$ Gebilde, palavra que contém em si a palavra Bild, (imagem, retrato, quadro). Gebilde pode ser traduzida, a depender do contexto, como composição, formação, forma, construção, construto, configuração, figura, e em combinação com o adjetivo sprachlich ou o substantivo Sprache, também como criação, produto ou produção lingüístico/a ou de linguagem. Aqui optamos por uma dessas traduções a depender do sentido que nos pareceu adequado enfatizar contextualmente e de acordo com a interpretação do texto que favorecemos. A palavra Bild encontra-se na raiz de outras palavras relevantes neste ensaio: Abbild (imagem, retrato, reprodução, cópia) e Urbild (original, protótipo, modelo, arquétipo). Ver a respeito também a nota 41 do ensaio "A tarefa do tradutor", publicada em BENJAMIN, Walter. Escritos sobre mito e linguagem (1915-1921). São Paulo: Ed.34, 2011.

${ }^{2}$ BENJAMIN, W. A tarefa do tradutor, p. 103

${ }^{3}$ Id.ibid., p. 104.

${ }^{4}$ Id.ibid., p. 108.

${ }^{5}$ BENJAMIN, W. Sobre a linguagem em geral e sobre a linguagem do homem., p. 64.

${ }^{6}$ BENJAMIN, W. A tarefa do tradutor, p. 112.

7 Id.ibid., p. 112-3.

8 Id.ibid., p. 114.

${ }^{9}$ Id.ibid. , p. 104.

${ }^{10}$ NÄGELE, Rainer. Echolalie, p. 21.

11 BENJAMIN, W. Sobre a linguagem em geral e sobre a linguagem do homem, p. 151. 